\title{
Spectrophotometric Analysis of the Relationship between Dissociation and Coloration, and of the Structural Formulas of Phenolphthalein in Aqueous Solution
}

\author{
Zenzo TAMURA, Seiji Aвe, Katsutoshi Ito and Masako MAEdA \\ School of Pharmaceutical Sciences, Showa University, Hatanodai, Shinagawa, Tokyo 142, Japan
}

\begin{abstract}
The absorption spectra of phenolphthalein $\left(\mathrm{H}_{2} \mathrm{PP}\right)$ in phosphate buffers of $\mathrm{pH} 5$ to 13 were analyzed in order to determine the features of the dissociation and coloration of $\mathrm{H}_{2} \mathrm{PP}$. The spectra demonstrated that HPP-, while keeping a $\gamma$-lactone ring, was colorless, and that only $\mathrm{PP}^{2-}$ was red, where $\mathrm{p} K_{1}=9.05$, and $\mathrm{p} K_{2}=9.50$; further, the reaction of hydroxide ion with $\mathrm{PP}^{2-}$ to produce colorless $\mathrm{PP}(\mathrm{OH})^{3-}$ was rather slow, where $\mathrm{p} K_{3}=12$. On the contrary, the color of the aqueous solution of phenolsulfonphthalein $\left(\mathrm{H}_{2}+\mathrm{PS}^{-}\right)$, having a zwitter ion structure and no lactone ring, was orange-red, which dissociated to yellow HPS ${ }^{-}$and finally to PS $^{2-}$, having a similar red color and absorption spectrum to $\mathbf{P P}^{2-}$. These results clearly demonstrate the relationship between the color and the prolonged conjugated system.
\end{abstract}

Keywords Phenolphthalein, phenolsulfonphthalein, absorption spectrum, structural formula and color, dissociation exponent

Phenolphthalein $\left(\mathrm{H}_{2} \mathrm{PP}\right)$ and phenolsulfonphtalein $\left(\mathrm{H}_{2} \mathrm{PS}\right)$ are the key compounds of various kinds of phthaleins and sulfonphthaleins, respectively. The structural formula and chemical name of $\mathrm{H}_{2} \mathrm{PS}$ had been postulated as a $\gamma$-sultone in almost all books; until recently, Yamaguchi et al. denied the $\gamma$-sultone and proposed the molecular structure of the zwitter ionic form of $\mathrm{H}_{2} \mathrm{PS}\left(\mathrm{H}_{2}{ }^{+} \mathrm{PS}^{-}\right)$using X-ray crystallography. ${ }^{1}$

On the contrary, $\mathrm{H}_{2} \mathbf{P P}$ having a $\gamma$-lactone ring is colorless, and its aqueous solution gives only one kind of red color in the alkaline region. The molecular structure of the species of red color had not been determined. Although Ozeki et al. estimated $\mathbf{P P}^{2-}$ as the red species, they reported that the value of $\mathrm{p} K_{1}(10.1)$ was larger than that of $\mathrm{p} K_{2}(9.3) .^{2} \quad$ These values are unreasonable since among the successive acid-dissociation constants, $K_{1}$ should always be larger than $K_{2}$.

In this paper, the absorption spectra of $\mathrm{H}_{2} \mathrm{PP}$ in phosphate buffers of various $\mathrm{pH}$ were analyzed in order to determine the features of the dissociation and coloration of $\mathrm{H}_{2} \mathrm{PP}$ while taking the spectra of its monoglucuronide and diphosphate, and the spectra of $\mathrm{H}_{2}{ }^{+} \mathrm{PS}^{-}$as references.

\section{Experimental}

\section{Materials}

Phenolsulfonphthalein was kindly supplied by Daiichi Pharmaceutical Co., Ltd. Phenolphthalein and phenolphthalein monoglucuronide (Wako Pure Chemical
Industries Ltd.), phenolphthalein diphosphate tetrasodium salt hydrate (Aldrich Chem. Co., Ltd.) and other chemicals were of analytical reagent grade.

\section{Buffers}

Phosphate buffers of $0.2 \mathrm{M}$ were prepared with sodium dihydrogenphosphate, hydrochloric acid, sodium hydroxide and redistilled water.

\section{Preparation of sample solutions}

After $3.21 \mathrm{mg}$ of $\mathrm{H}_{2} \mathrm{PP}$ was dissolved in $1 \mathrm{ml}$ of ethanol and diluted to $10 \mathrm{ml}$ with the buffer of $\mathrm{pH} 10$, the resulting solution $(1 \mathrm{mM})$ was diluted 100 times with the buffers to obtain $10^{-5} \mathrm{M}$ sample solutions of $\mathrm{H}_{2} \mathrm{PP}$.

A $1 \mathrm{mM}$ solution of $\mathrm{H}_{2}^{+} \mathrm{PS}^{-}$in the buffer of $\mathrm{pH} 8$ was diluted 200 times with the buffers to obtain $5 \times 10^{-6} \mathrm{M}$ sample solutions of $\mathrm{H}_{2}{ }^{+} \mathrm{PS}^{-}$. Similar methods were used to prepare $10^{-5} \mathrm{M}$ sample solutions of phenolphthalein diphosphate and phenolphthalein monoglucuronide.

\section{Instruments and measurements}

A Hitachi U-3210 spectrophotometer with a scan speed of $120 \mathrm{~nm} / \mathrm{min}$ and a band path of $2 \mathrm{~nm}$, and a pair of matching cells of $1 \mathrm{~cm}$ light pass were used to measure the absorption spectra at $25 \pm 2^{\circ} \mathrm{C}$, where the buffers were used as references. A Toa-HM-20E glass electrode $\mathrm{pH}$ meter was used at $25 \pm 2^{\circ} \mathrm{C}$ and calibrated with standard solutions of $\mathrm{pH} 1.68,4.01,6.86$ and 10.02. A Macintosh Quadra 840AV Personal Computer of Apple Co., Ltd. was used to analyze the absorption spectra. 


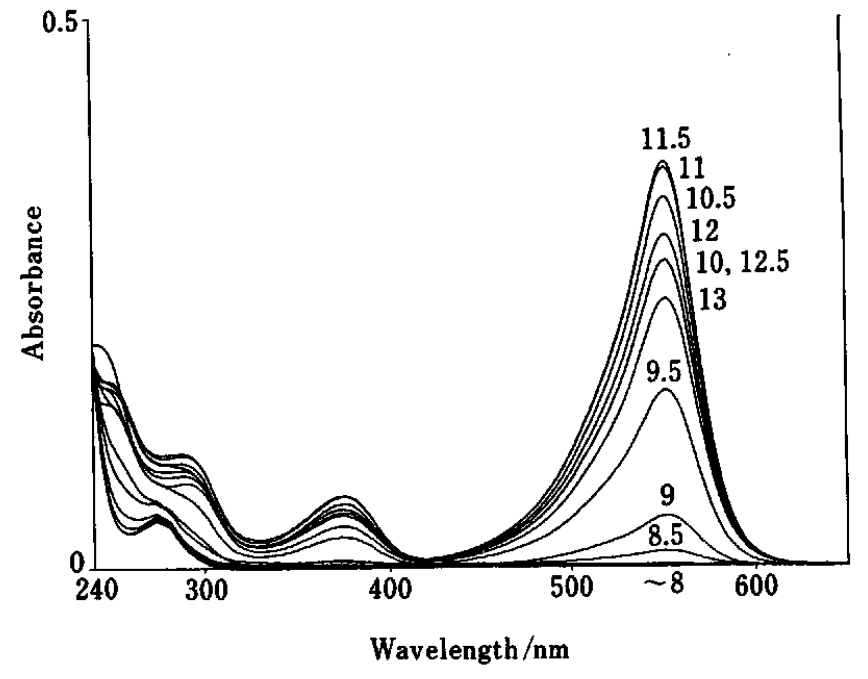

Fig. 1 Absorption spectra of phenolphthalein. The final concentration is $10^{-5} \mathrm{M}$. The rough $\mathrm{pH}$ values of solutions are given on the spectra.

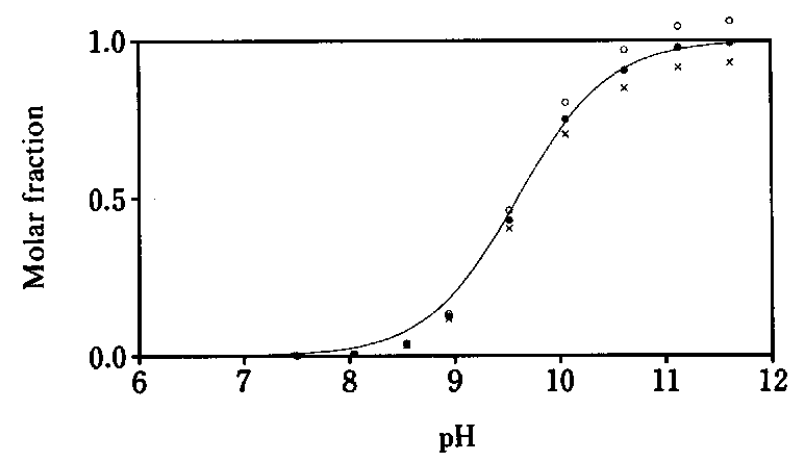

Fig. 2 Graphic estimation of the molar fraction of $\mathbf{P P}^{2-}$, assuming its absorbance to be $0.35(O), 0.375(\odot)$ and 0.40 $(\times)$. - : the theoretical curve for a monobasic acid with $\mathrm{p} K=9.6$.

\section{Results and Discussion}

The absorption spectra of the $\mathrm{H}_{2} \mathrm{PP}$ solutions in Fig. 1 were measured as soon as possible in the alkaline region, since the spectra were found to change with the speed, depending on the concentration of the hydroxide ion (as described later).

In the visible region, since the absorption spectra of $\mathrm{H}_{2} \mathrm{PP}$ had only one maximum point at $552.8 \mathrm{~nm}$, the molar fractions of the red species were calculated from the absorbances at $552.8 \mathrm{~nm}$ by trial and error (Fig. 2). The values obtained by assuming the absorbance of the species to be 0.375 indicated a $\mathrm{pK}$ of approximately 9.6. However, the values at $\mathrm{pH}$ below 9 were lower than theoretical ones for a monobasic acid (Fig. 2). These results indicated the presence of a colorless species ( $\mathrm{HPP}^{-}$) between $\mathrm{H}_{2} \mathrm{PP}$ and the red

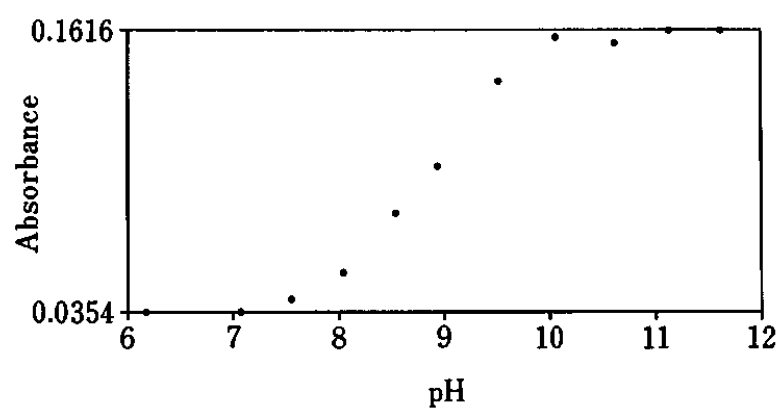

Fig. 3 Preliminary estimation of $\mathrm{p} K_{1}$ of $\mathrm{H}_{2} \mathrm{PP}$ by drawing with the absorbance at $255.2 \mathrm{~nm}$.

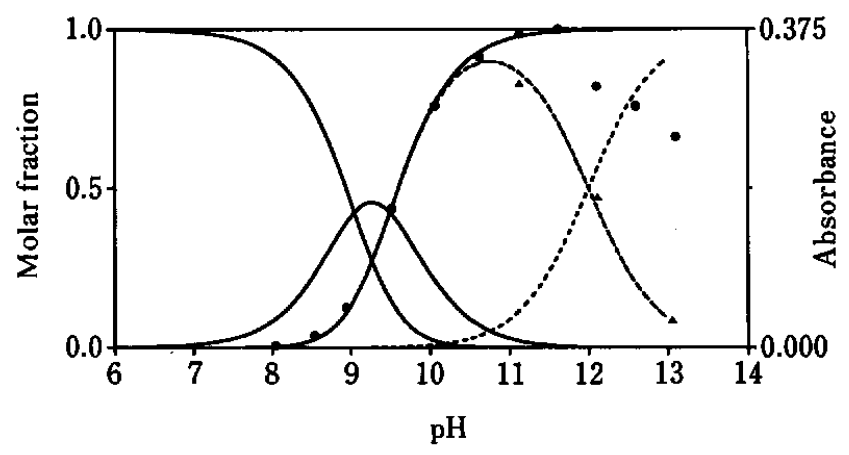

Fig. 4 Molar fractions of $\mathrm{H}_{2} \mathrm{PP}, \mathrm{HPP}^{-}, \mathrm{PP}^{2-}$ and $\mathrm{PP}(\mathrm{OH})^{3-}$. Theoretical curves assuming $\mathrm{p} K_{1}=9.05$ and $\mathrm{p} K_{2}=9.50(-)$, and additionally $\mathrm{p} K_{3}=12(-)$, where the acid dissociation constant of $\mathrm{HA}$ is defined as $K=a_{\mathrm{H}+}\left[\mathrm{A}^{-}\right] /[\mathrm{HA}]$. The observed absorbances at $552.8 \mathrm{~nm}$ under the conditions given in Fig. $1(\Theta)$, and after standing for equilibration (A).

species $\left(\mathbf{P P}^{2-}\right)$.

From the spectra in the ultraviolet region, $255.2 \mathrm{~nm}$ was selected, at which point the absorbance maintained a constant value at $\mathrm{pH}$ above 10 , and decreased with a lowered $\mathrm{pH}$. A similar sigmoid curve was obtained, where a $\mathrm{p} K$ value of approximately 9 was indicated (Fig. 3).

Consequently, as shown in Fig. 4, the molar fractions (-) of $\mathrm{H}_{2} \mathrm{PP}, \mathrm{HPP}^{-}$and $\mathrm{PP}^{2-}$ were calculated using the assumed $\mathrm{p} K_{1}$ and $\mathrm{p} K_{2}$ values and the trial-anderror method, to coincide with the observed values of $\mathrm{PP}^{2-}$ (@) from the following equations for a dibasic acid: ${ }^{3}$

$$
\begin{aligned}
& {\left[\mathrm{H}_{2} \mathrm{PP}\right]+\left[\mathrm{HPP}^{-}\right]+\left[\mathrm{PP}^{2-}\right]=\Sigma \mathrm{P},} \\
& a_{\mathrm{H}^{2}}+a_{\mathrm{H}+} \times 10^{-\mathrm{p} K_{1}}+10^{-\mathrm{p} K_{1}-\mathrm{p} K_{2}}=\Sigma, \\
& {\left[\mathrm{H}_{2} \mathrm{PP}\right] / \Sigma \mathrm{P}=a_{\mathrm{H}+}^{2} / \Sigma,} \\
& {\left[\mathrm{HPP}^{-}\right] / \Sigma \mathrm{P}=a_{\mathrm{H}+} \times 10^{-\mathrm{p} K_{1}} / \Sigma,} \\
& {\left[\mathrm{PP}^{2-}\right] / \Sigma \mathrm{P}=10^{-\mathrm{p} K_{1}-\mathrm{p} K_{2}} / \Sigma .}
\end{aligned}
$$

The absorbance at $552.8 \mathrm{~nm}$ equals $\varepsilon_{\mathrm{PP} 2}\left[\mathrm{PP}^{2-}\right]$. 


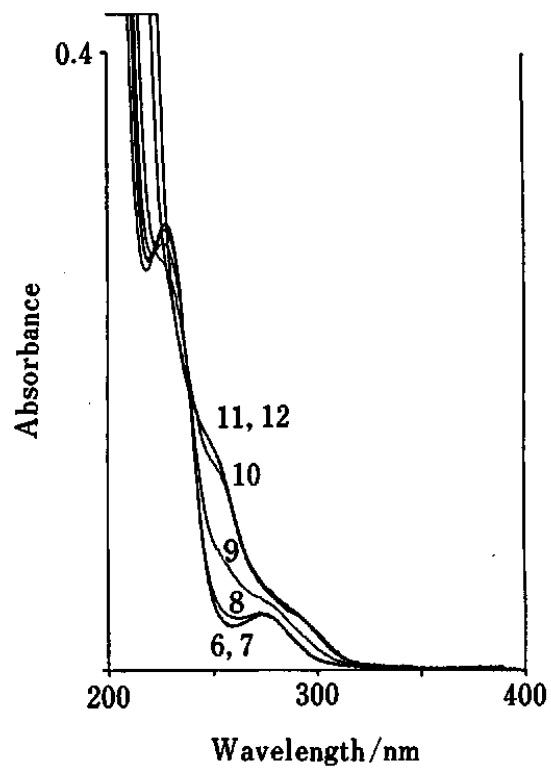

Fig. 5 Absorption spectra of phenolphthalein monoglucuronide. The final concentration is $10^{-5} \mathrm{M}$. In this case, water was used as the reference.

As the result, the values of $\mathrm{p} K_{1}$ and $\mathrm{p} K_{2}$ were estimated to be 9.05 and 9.50 , respectively.

Phenolphthalein diphosphate, in which both of the hydroxy groups were substituted, showed a similar absorption spectrum to that of $\mathrm{H}_{2} \mathrm{PP}$ in the 6 to $11 \mathrm{pH}$ range where the $\gamma$-lactone ring was proved to be stable.

As shown in Fig. 5, phenolphthalein monoglucuronide, in which one of the hydroxy groups was substituted,

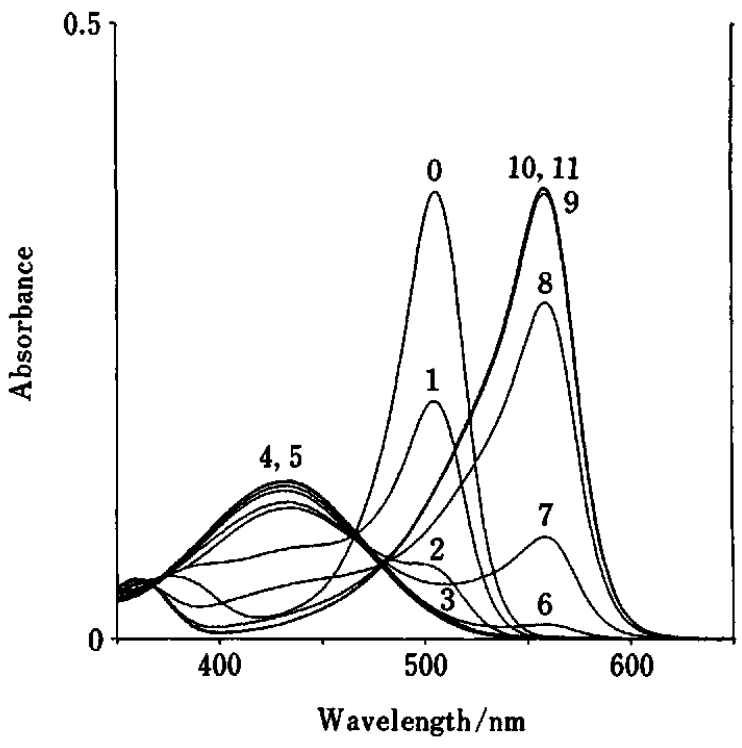

Fig. 6 Absorption spectra of phenolsulfonphthalein. The final concentration is $5 \times 10^{-6} \mathrm{M}$.

showed a similar spectrum to that of $\mathrm{H}_{2} \mathrm{PP}$ at $\mathrm{pH}$ below 7 , while another spectrum, perhaps corresponding to HPP $^{-}$, appeared at a $\mathrm{pH}$ above 11 . These spectra, having an isosbestic point, demonstrated the existence of two kinds of molecular species in the range of pH 6 to 12 with a $\mathrm{p} K$ value of about 9 . The spectral change which occurred in the ultraviolet region in an alkaline solution indicated the dissociation of the hydroxy group together with the maintenance of the lactone ring.

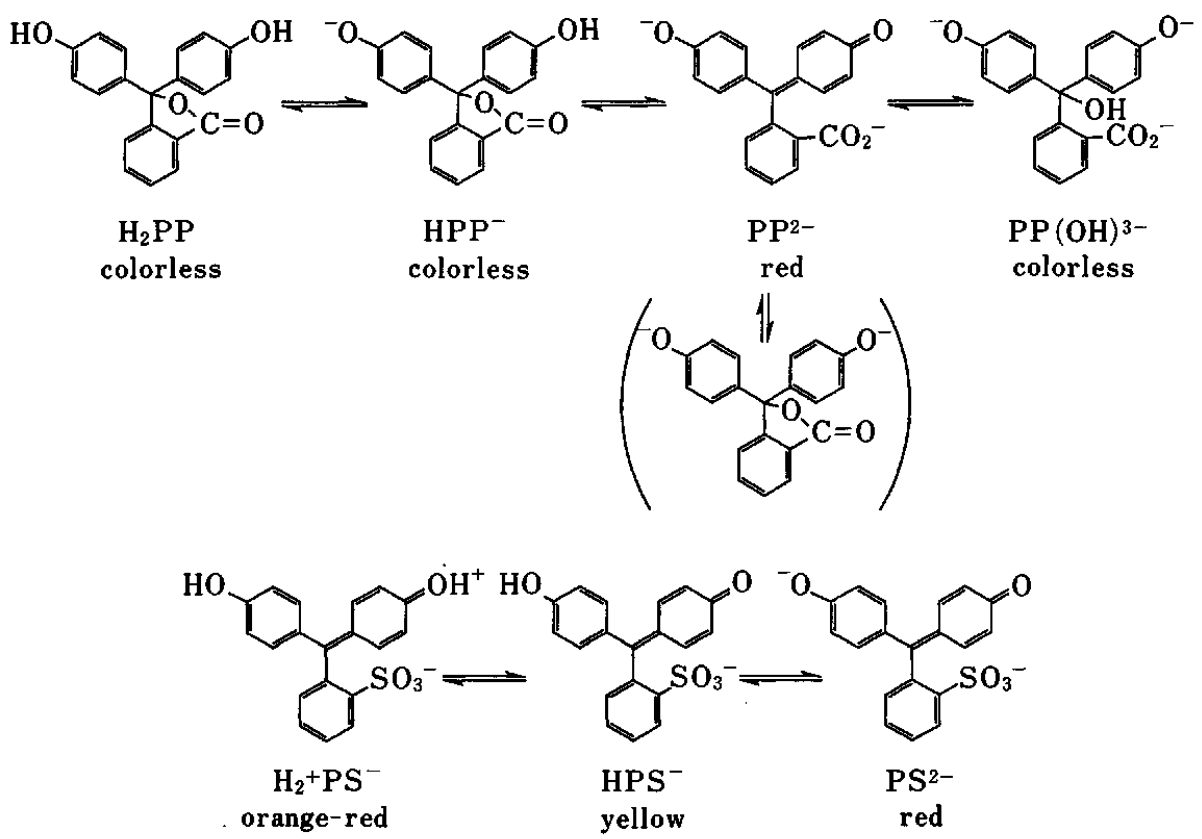

Fig. 7 Structural formulas and colors of the existent molecular species in aqueous solutions of $\mathrm{H}_{2} \mathrm{PP}$ and $\mathrm{H}_{2}+\mathrm{PS}^{-}$. 
The lactone form of colorless HPP- was further supported by a comparison of the spectra of $\mathrm{H}_{2} \mathrm{PP}$ (Fig. 1) with those of orange red $\mathrm{H}_{2}{ }^{+} \mathbf{P S}-$, which was a strong acid possessing no lactone ring ${ }^{1}$, and dissociated a phenolic proton to yellow HPS ${ }^{-}$at $\mathrm{pH} 4$ to 5 , as shown in Fig. 6 (also in Fig. 7); $\mathrm{p} K_{1}=1.2$ was calculated from the spectra of pH 0,1 and 4 using a similar trial-and-error method to that in Fig. 4 , and $\mathrm{p} K_{2}=7.70$ was obtained from the absorbances at $559.0 \mathrm{~nm}$.

The reaction of hydroxide ion with $\mathrm{PP}^{2-}$ to produce $\mathrm{PP}(\mathrm{OH})^{3-}$ was rather slow, and caused a disturbance of the spectra shown in Fig. 1. From the rates of the decrease in the absorbances at $552.8 \mathrm{~nm}$ with solutions of $\mathrm{H}_{2} \mathrm{PP}$ at a pH above 11 , the rate constant of the $\mathrm{OH}^{-}$ addition reaction was estimated to be about $30 \mathrm{M}^{-1} \mathrm{~h}^{-1}$ at $25^{\circ} \mathrm{C}$. By a measurement after a sufficient standing time, $\mathrm{p} K_{3}$ of $\mathrm{H}_{2} \mathrm{PP}$ was determined to be 12 using the equations for a tribasic $\operatorname{acid}^{3}$ (Fig. 4, ---) together with the spectrum of $\mathrm{PP}(\mathrm{OH})^{3-}$, having an absorption maximum at $244 \mathrm{~nm}$.

From the data obtained above, the structural formulas of existent molecular species in aqueous solutions of $\mathrm{H}_{2} \mathrm{PP}$ and $\mathrm{H}_{2}{ }^{+} \mathrm{PS}-$ were estimated (Fig. 7).

Figures 1, 6 and 7 clearly demonstrate the differences between $\mathrm{H}_{2} \mathrm{PP}$ and $\mathrm{H}_{2}{ }^{+} \mathrm{PS}^{-}$. Both $\mathbf{P P}^{2-}$ and $\mathrm{PS}^{2-}$, having analogous structural formulas, display a red color with similar absorption spectra. There remains a possibility of partially maintaining the lactone ring in $\mathrm{PP}^{2-}$, as in the parenthesis of Fig. 7, since the molar extinction coefficient of $\mathbf{P P}^{2-}$ is much lower than that of $\mathrm{PS}^{2-}$. On the contrary, $\mathrm{H}_{2} \mathrm{PP}$ and $\mathrm{HPP}^{-}$, which maintain the $\gamma$ lactone ring, are colorless because of isolated benzenerings, while $\mathrm{H}_{2}^{+} \mathrm{PS}^{-}$and $\mathrm{HPS}^{-}$, which maintain a prolonged conjugate system, are colored.

Further comparisons with their O-bridged analogous, fluorescein $\left(\mathrm{H}_{2} \mathrm{FL}\right)$ and sulfonefluorescein $\left(\mathrm{H}_{2}{ }^{+} \mathrm{SF}^{-}\right)$are interesting. ${ }^{3}$
Table 1 The $\mathrm{p} K$ values of the molecular species of $\mathrm{H}_{2} \mathrm{PP}$, $\mathrm{H}_{2}{ }^{+} \mathrm{PS}^{-}, \mathrm{H}_{2} \mathrm{FL}$ and $\mathrm{H}_{2}+\mathrm{SF}^{-\mathrm{a}}$

\begin{tabular}{ccccc}
\hline \multirow{2}{*}{ Charge } & \multicolumn{5}{c}{ Neutral form } \\
\cline { 2 - 5 } & $\mathrm{H}_{2} \mathrm{PP}$ & $\mathrm{H}_{2} \mathrm{FL}$ & $\mathrm{H}_{2}{ }^{+} \mathrm{PS}^{-}$ & $\mathrm{H}_{2}{ }^{+} \mathrm{SF}^{-}$ \\
\hline $1+$ & & $2.24^{\mathrm{b}}$ & & \\
0 & 9.05 & 4.20 & 1.2 & $3.10^{\mathrm{b}}$ \\
$1-$ & 9.50 & 6.39 & 7.70 & 6.25 \\
$2-$ & 12 & & & \\
\hline
\end{tabular}

a. The acid dissociation constant of $\mathrm{HA}$ is defined as

$$
K=a_{\mathbf{H}+}\left[\mathrm{A}^{-}\right] /[\mathrm{HA}]
$$

The zwitter ionic structures of $\mathrm{H}_{2}{ }^{+} \mathrm{PS}^{-}$and $\mathrm{H}_{2}{ }^{+} \mathrm{SF}^{-}$were estimated by Yamaguchi ${ }^{1}$ et al. and $\mathrm{Kanazawa}^{4}$ et al., respectively.

b. The values are taken from ref. 3 .

As shown in Table 1, the stability of the lactone ring in $\mathrm{H}_{2} \mathrm{PP}$ is greatly lowered due to the fixed plane structure in $\mathrm{H}_{2} \mathrm{FL}$, which thus has different $\mathrm{p} K$ values from those of $\mathrm{H}_{2} \mathrm{PP}$. Further, the bridging oxygen in $\mathrm{H}_{2}{ }^{+} \mathrm{SF}^{-}$will suppress the dissociation of $=\mathrm{OH}^{+}$with a resonance effect, and accelerate that of $-\mathrm{OH}$ with an inductive effect to cause the larger $\mathrm{p} K_{1}$ and smaller $\mathrm{p} K_{2}$ values of $\mathrm{H}_{2}{ }^{+} \mathrm{SF}$ than those of $\mathrm{H}_{2}^{+} \mathrm{PS}^{-}$.

\section{References}

1. K. Yamaguchi, Z. Tamura and M. Maeda, in preparation.

2. T. Ozeki, H. Morikawa and H. Kihara, Bunseki Kagaku, 42, 887 (1993).

3. Z. Tamura, T. Morioka, M. Maeda and A. Tsuji, Bronseki Kagaku, 43, 339 (1994).

4. H. Kanazawa, K. Senga, Z. Tamura and Y. Iitaka, Anal. Sci., 10, 521 (1994). 